\title{
Homoeopathic Treatment as an Add-On for Minimizing After Effects of Conventionally Treated Cancer Patients: A Simple Randomized Pilot Study- Protocol from Northeast India Perspective
}

\author{
${ }^{1}$ Clinical Research Unit for Homoeopathy (under Central Council \\ for Research in Homeopathy, Ministry of AYUSH, Government of \\ India), Aizawl, Mizoram, India \\ ${ }^{2}$ Central Council for Research in Homoeopathy, Ministry of AYUSH, \\ Government of India, New Delhi, India \\ ${ }^{3}$ Central Council of Homoeopathy (under Ministry of AYUSH, \\ Government of India), Janakpuri, New Delhi, India \\ ${ }^{4}$ Population Based Cancer Registry-Guwahati, National Cancer \\ Registry Programme, National Centre for Disease Informatics and \\ Research, Indian Council of Medical Research, Dr. B Borooah Cancer \\ Institute, Guwahati, Assam, India
}

Pawan Sharma ${ }^{1}$ Bindu Sharma ${ }^{2}$ Tanya Aggarwal ${ }^{3}$ Manoj Kalita ${ }^{4}$

\begin{abstract}
Address for correspondence Tanya Aggarwal, BHMS, MD, Central Council of Homoeopathy (under Ministry of AYUSH, Government of India), Opposite D Block, Janakpuri, New Delhi 110058, India (e-mail: dr.tanyaaggarwal@gmail.com).
\end{abstract}

\begin{abstract}
Keywords

- cancer

- side effect

- add-on

- chemotherapy

- homoeopathic treatment

- north-east India

- protocol

The north-eastern region of India accounts for a total of 37,448 cancer cases reported from 11 population-based cancer registries (PBCRs) from 2012 to 2014. Studies suggest that with the holistic approach adopted by homoeopathy, not only the symptoms like cancer pain are alleviated, but also the overall well-being of the patient. Homoeopathy can be beneficial to minimize the treatment-induced adverse effects like radiation-induced mucositis, skin reactions, postoperative seroma, bleeding, and complications associated with the use of surgery, chemotherapy, and radiation therapy. This study intends to provide homoeopathic services as an add-on to conventional treatment to the patients referred for homoeopathic treatment after their due consent. The primary objective is to study the usefulness of homoeopathic medicines for combating the suffering of cancer patients having complaints other than cancer. A sample size of 70 patients per group in two arms (Arm A: standard allopathic drug and Arm B: standard allopathic drug + homoeopathic treatment) will be recruited using simple random sampling without repetition. Cancer patients reporting complaints other than cancer itself and suffering from the after-effects of cancer treatment with chemotherapy and radiation therapy to any reputed cancer institute will be screened and will be recruited according to inclusion and exclusion criteria. After completion of the six months study duration, results will be able to predict the role of homoeopathic treatment as an add-on to conventionally treated cancer patients to minimize the suffering other than cancer and the after-effects of chemotherapy and radiation therapy. If found significant, this could prove to be a contribution in the health care system in handling cancer cases that are very difficult to treat. Further, the cost-effectiveness of homoeopathy will enable developing countries to manage such a disease effectively.
\end{abstract}

published online June 8, 2021
DOI https://doi.org/

10.1055/s-0041-1730099

ISSN 2454-6798 (c) 2021. Spring Hope Cancer Foundation \& Young Oncologist Group of Asia.

This is an open access article published by Thieme under the terms of the Creative Commons Attribution-NonDerivative-NonCommercial-License, permitting copying and reproduction so long as the original work is given appropriate credit. Contents may not be used for commercial purposes, or adapted, remixed, transformed or built upon. (https://creativecommons.org/licenses/by-nc-nd/4.0/).

Thieme Medical and Scientific Publishers Pvt. Ltd. A-12, 2nd Floor, Sector 2, Noida-201301 UP, India 


\section{Introduction}

The Northeastern region of India comprises eight states, namely, Arunachal Pradesh, Assam, Manipur, Meghalaya, Mizoram, Nagaland, Sikkim, and Tripura. A total of 37,448 cancer cases are reported from 11 population-based cancer registries (PBCRs) of 8 states during 2012 to 2014. Of these, male cases outnumber females, except in Manipur state. The number of cases ranges from 334 in Pasighat, Arunachal Pradesh and 5,463 in Kamrup district of Assam alone to 6,330 in Tripura. The average risk that a person will develop cancer in their lifetime ( $0-74$ years) is $\sim 1$ in 5 for both sexes in Kamrup urban district. Risk factors are tobacco, alcohol, obesity, and so forth. Among males, lung cancer shows statistical significance increase than cancer of hypopharynx and esophagus. Incidence rate of breast and gallbladder cancer in females increased significantly from the year 2003 to 2014. Case fatality ratio in males is $32.9 \%$ whereas in females is $21.9 \%$. For both sexes the case fatality ratio is $21.8 \%$.

Cancer affects not only the patient in terms of pain, suffering, and quality of life (QoL) but their families too who face emotional, physical, and financial hardship owing to this life-threatening illness. The potential of homoeopathic medicines in preclinical and clinical stages of cancer has not been vastly explored. However, some preclinical studies have demonstrated the anticancer properties of homoeopathic medicines on different cell lines. ${ }^{1-10}$ The Central Council for Research in Homoeopathy (CCRH) has also conducted preclinical studies with Bose Institute, Kolkata, wherein the antitumorigenic activity of Calcarea carbonica, Thuja occidentalis, and sulphur were identified and their molecular mechanism(s) of action underlying apoptosis and tumor regression were delineated. ${ }^{11-13}$ Studies indicate that cancer pain can be palliated with homoeopathic treatment. ${ }^{14,15}$ PBCR of 2012 to 2014 recommends radiotherapy and palliative care for the treatment of cancer. Palliative care prevents and relieves suffering through early identification, correct assessment, and treatment of pain and other problems, whether physical, psychosocial, or spiritual. ${ }^{16}$ So homoeopathy can play a key role in palliative care treatment as it is evidenced that homoeopathic treatment is safe and causes minimal to no adverse effects. This is the main reason for its popularity in the world ${ }^{17}$ and it can be successfully integrated in supportive care integrative oncology service. ${ }^{18-20}$ The overall well-being of a cancer patient can be achieved by homoeopathy; positive results for emotional, physical, psychological, and QoL have been reported, evaluated on the basis of different validated questionnai res. ${ }^{13-15,21,22}$ Complications associated with the use of chemotherapy and radiation therapy may decrease the effectiveness of treatment by the need to reduce the dose or increase of the interval between cycles..$^{23}$ In this sphere also, homoeopathy can be used to minimize the treatment-induced adverse effects. Homoeopathic remedies can alleviate chemotherapy and radiation therapy side effects such as nausea, vomiting, fatigue, loss of appetite, depression, radiation-induced mucositis, and skin complaints ${ }^{24-27}$ without antidoting the positive effects. A prospective observational study of two independent cohorts showed an improvement of QoL as well as a tendency of fatigue symptoms to decrease in cancer patients under complementary homeopathic treatment in comparison to conventionally treated cancer patients. ${ }^{28}$

\section{Background and Justification}

Clinical trials are prospective research studies on human subjects, which clarify the new treatment modalities (novel vaccine, drugs, supplements, medical devices, etc.). Clinical trials provide guidance for further study or comparison with other modalities. Clinical trials are important to ensure the safety and efficacy of a drug. Modern system of medicine requires new medicine with the emergence of new diseases and hence the need of clinical trial is in evidence. Homoeopathic Pharmacopoeia of India (HPI) is the official book of standards of homeopathic medicine in terms of Schedule-II of the Drugs and Cosmetics Act, 1940, and Rules, 1945. Indian manufacturers are legally bound to manufacture homoeopathic medicine as per the standards and methodology given in the HPI. In this study we are using the drugs mentioned in the HPI which are proved on healthy human being. Homoeopathic drugs are tested in preclinical study setting., ${ }^{2,9-13,29-40}$ Further some studies show the effectiveness of the homeopathic drugs in malignant cases. ${ }^{14,41-45}$ But the objective of this study is to give supportive care to cancer patients using homoeopathic treatment as an add-on supportive therapy for minimizing the after effects and side effects of conventionally treated cancer patients. Clinical studies have found that homoeopathy is efficacious in the treatment of radiation-induced mucositis, ${ }^{24}$ joint pain related to aromatase inhibitors, ${ }^{15}$ radiation-induced itching, ${ }^{25}$ skin reactions during radiotherapy, ${ }^{26}$ nausea, vomiting, fatigue, loss of appetite, depression, and so forth. Also, homoeopathy has a role in cancer treatment as supportive medicine, ${ }^{14,21,27}$ with better survival. ${ }^{20}$ Cancer is not only a burden to the society but also causes distressing symptoms and a huge socioeconomic loss to the patient as well as to the country. Though the treatment is comprises surgery, radiotherapy, and chemotherapy, the latter has been frequently advised to the patients as the mainline treatment until now. But chemotherapy is always accompanied with side effects that disrupt QoL of the patient. Chemotherapy, while destroying cancer cells, also damages healthy cells, whereas homoeopathic preparations are known for selectively targeting the cancer cells while sparing the healthy counterparts. ${ }^{46}$ There are several studies which report that adding classical homoeopathy to conventional cancer care significantly improves the QoL and global health status. ${ }^{28,47}$ Studies have also reported positive effects of homoeopathy on fatigue symptoms in post chemotherapy patients. ${ }^{28,48}$ Traumeel, a homeopathic combination medicine, is known for reducing pain in cancer patients. ${ }^{49}$ Preliminary data from a study suggested that there is some beneficial effect of homeopathy in chemotherapy-induced stomatitis, but there is no convincing evidence for the efficacy of homeopathic remedies for other adverse effects in cancer treatments. ${ }^{50}$ Few studies show the positive role of homoeopathy in controlling adverse effects of CT with 
variable success including alleviating the most distressing symptoms as well as the QoL. ${ }^{48,51-53}$

\section{Objective}

The primary objective is to study the usefulness of homoeopathic medicines for combating the suffering of cancer patients having complaint other than cancer using the Edmonton Symptom Assessment Scale revised version (ESAS-R), whereas secondary objectives are to assess the QoL using European Organization for Research and Treatment of Cancer-Quality of Life Questionnaire (EORTC QLQ-C30). Permission to use these scales should be taken from concerned scientific group.

The ESAS-R provides symptoms like pain, tiredness, drowsiness, nausea, lack of appetite, shortness of breath, depression, anxiety, and well-being, and any other complaint, if any. Each complaint has been graded 0 to 10 with best/no complaint to worst. The ESAS-R is intended to capture the patient's perspective on symptoms. However, in some situations it may be necessary to obtain the caregiver's perspective.

Health-related quality of life:The EORTC QLQ-C30is an integrated system for assessing the QoL of cancer patients participating in clinical trials and other types of research in which patient-reported outcomes are collected. The EORTC QLQ-C30 is designed for use with a wide range of cancer patient populations. The EORTC QLQ-C30 incorporates nine multi-item scales-five functional scales (physical, role, cognitive, emotional, and social functioning); three symptom scales (fatigue, pain, and nausea/vomiting); and a global health status/QoL scale. Six single-item scales are also included (dyspnoea, insomnia, appetite loss, constipation, diarrhea, and financial difficulties).

\section{Study Design}

Sample size was estimated to detect a difference of 1.2 points between two groups in pain intensity improvement based on recommendation of the Initiative on Methods, Measurement, and Pain Assessment in Clinical Trials (IMMPACT) in the chronic pain trial. A sample size of 70 patients per group provided at least $80 \%$ power to detect the difference at a significance level of 0.05 using a two-tailed test.

- Sampling: simple random sampling without repetition will be used.

- Study group: two arms:

- Arm A: standard allopathic drug.

- Arm B: standard allopathic drug + homoeopathic treatment.

\section{Statistical Methods}

For this comparison, $t$-tests and analysis of variance(ANOVA) will be done for continuous variables and chi-square or Fisher exact tests will be performed for categorical variables. To achieve the objective a series of regression analyses were performed to ascertain associations between variables. A 95\% confidence interval $(\mathrm{CI})$ along with $p$-value will be calculated to describe the association. A $p$-value $<0.05$ was considered as statistically significant. IBM SPSS Statistics and GraphPad (Prism 5, Medcal, and Epi info software) will be used for all the statistical analysis.

\section{Inclusion}

The inclusion criteria are as follows:

- Patients willing to sign written informed consent.

- Patients with any stage of any type of cancer undergoing cancer treatment at a reputed cancer institute.

- Patient having any two of the following symptomsanorexia, nausea, vomiting, diarrhea, constipation, cough, shortness of breath, taste alterations, dry mouth, mucositis, dermatitis, conjunctivitis, lachrymation, hair loss, sensory neuropathy, flu-like symptoms, reduced blood count (but hemoglobin percentage [Hb\%] not less than $6.5 \mathrm{mg} / \mathrm{dL}$ ), cramping, urinary frequency, vaginal irritation, impotence, skin redness, fatigue, myalgia, anxiety, depression, and drowsiness.

- The patient should not be under homoeopathic treatment in the last 2 weeks.

\section{Exclusion Criteria}

The exclusion criteria are as follows:

- Patients who were not willing to volunteer for the study.

- Patients who developed serious complications like renal failure, idiosyncratic reactions, and severe medicinal aggravation.

- Patients requiring emergency surgical intervention like in the case of gastrointestinal obstruction.

\section{Withdrawal}

No serious risks are anticipated in this study due to homoeopathic intervention. In case the medicine does not give relief or aggravates the present condition and the disease progresses further, immediately care will be taken by providing the proper dose of medicine and/or rescue medicine (clinical homoeopathic treatment) where indicated. If any adverse event occurs, the participant will be withdrawn from the study.

\section{Subject Recruitment and Screening}

Patients reporting with complaints other than cancer itself and suffering from the after effects of cancer treatment with chemotherapy and radiation therapy to any reputed cancer institute will be screened for treatment.

\section{Administration and Compliance}

The first dose of the study drug will be administered under direct observation of the study physician in the hospital. Patients will be advised to take rest of the medication as per the study protocol and their compliance will be monitored in 15-day intervals or as per requirement. 
Time Allocation for Study

Time allocation for the study is as follows:

- Screening and enrollment for 2 months.

- Treatment for 3 months from the date of screening.

- Data analysis for 1 month.

\section{Homoeopathic Intervention}

\section{Procurement and Dispensing of Medicine}

Procurement and dispensing of medicine will be done as follows:

- Homoeopathic medicines in dilutions of centesimal potency (6C, 30C, 200C, and $1 \mathrm{M}$ ) for the study will be procured from any of the approved good manufacturing practices (GMP) firms.

- Globules/pills of size 30 will be used for medicating dilutions and dispensing alcohol will be used for preparing placebo resembling the medicine. These globules will be procured from same firms. One dose will constitute 4 globules moistened with the medicine or placebo.

- Investigator/pharmacist will dispense the homoeopathic medicine/placebo to the patients as per protocol.

\section{Method of Selection of Individualized Homoeopathy Medicines}

- Selection of the medicine will be done after case-taking on the basis of totality of symptoms.

- Repertorization shall be done using Hompath software.

Only one medicine whose portrait confirms in the Materia Medica will be selected as the first prescription with justification for the respective patient.

Follow-up treatment: Each patient will be followed-up (if necessary telephonically) at entry and on every third day or as per requirement.

- ESAS-R and EORTC QLQ-C30 will be filled at entry and on every third day till 3 months.

- Complete hemogram is to be done at entry and on every month till 3 months.

- Final assessment will be done after 3 months. It will include the filling of ESAS-R and EORTC QLQ-C30 questionnaires. Final analysis will be done by the statistician as per the directions given in the module of the scales.

- If the patient does not report on a fixed date effort will be made to contact him/her in any way. The data will be maintained in an Excel sheet so that it can be procured every month and when necessary for interim analysis.

Follow-up and second prescription: Follow-up of each case for the second prescription will be done in comparison to the symptoms at baseline. Subjective and objective amelioration and aggravation; new symptoms, if any; or no change with symptoms persisting will be noted down according to the proforma ( $\mathbf{- T a b l e ~} \mathbf{1}$ ).

\section{Degree of Improvement}

The various degrees of improvement are listed as follows:
- Marked-more than 75\% improvement in symptom score from baseline score.

- Moderate-50\% to less than 75\% improvement in symptom score from baseline score.

- Mild-25\% to less than 50\% improvement in symptom score from baseline score.

- Not significant-less than $25 \%$ improvement in symptom score from baseline score.

- Not improved-no change in symptom score from baseline score after sufficient trial of best-indicated drug has been done.

- Worse-increase of symptom score from baseline score.

- Status quo-no change of score from baseline score.

- Referred-referred for other therapy in the eventuality of any adverse event.

- Withdrawal-patient withdraws consent or refuses further treatment.

- Drop out-patient does not fulfill conditions as per the protocol.

The concept of this research is reflected in - Fig. 1.

\section{Safety and Adverse Events}

At each contact with the subject, the investigator must seek information on adverse events by specific questioning as per "Reporting form for suspected adverse reactions-National Pharmacovigilance Programme for ASU \& H Drugs" and reported immediately to Pharmacovigilance Centre.

\section{Data Handling and Record Keeping}

The patients will be informed by the investigator that all trial results recorded will be treated in strict confidence. During documentation and analysis of the trial, the individual patients will only be identified by their patient number, whereas the name of the patient and any personal data are subject to the data protection regulations. The investigator will be responsible for the completeness and accuracy of the study materials.

\section{Study Monitoring, Auditing, and Inspecting}

The study conducted in any suitable study site will be monitored according to the strict principles. The investigator will allocate adequate time for such monitoring activities. The investigator will permit study-related monitoring, audits, and inspections by the ethical committee, institutional review board, or government regulatory bodies of all study-related documents (source documents, regulatory documents, data collection instruments, study data, etc.).

\section{Ethical Considerations}

This study is to be conducted according to standards of good clinical practice. This trial will be conducted in accordance with the requirements of the Declaration of Helsinki. This consent form will be submitted with the protocol for review and approval by the ethics committee (EC) for the study. 
Table 1 Follow-up and second prescription

\begin{tabular}{|c|c|c|c|c|c|}
\hline $\begin{array}{l}\text { Symptoms } \\
\text { at baseline }\end{array}$ & Amelioration & $\begin{array}{l}\text { Aggravation (indicate } \\
\text { which type of aggravation) }\end{array}$ & $\begin{array}{l}\text { New symptoms, } \\
\text { if any }\end{array}$ & $\begin{array}{l}\text { No change with } \\
\text { symptoms persisting }\end{array}$ & $\begin{array}{l}\text { Prescription with } \\
\text { justification }\end{array}$ \\
\hline & $\begin{array}{l}\text { Not to disturb } \\
\text { the action of the } \\
\text { medicine } \\
\text { (ref. Kent's 4th } \\
\text { observation) }\end{array}$ & $\begin{array}{l}\text { A prolonged aggravation } \\
\text { without amelioration: } \\
\text { reassess the case and } \\
\text { observe the changes. } \\
\text { If the same medicine is } \\
\text { indicated, prescribe in } \\
\text { suitable potency (ref. } \\
\text { Kent's 1st observation). If } \\
\text { another medicine is indi- } \\
\text { cated, prescribe in lower } \\
\text { potency. } \\
\text { Long aggravation, but } \\
\text { slow and final improve- } \\
\text { ment: prescribe placebo, } \\
\text { till the action of medicine } \\
\text { is complete (ref. Kent's } \\
\text { 2nd observation). } \\
\text { Aggravation is quick, } \\
\text { short, and strong with } \\
\text { rapid improvement of the } \\
\text { patient (homoeopathic } \\
\text { aggravation): discontinue } \\
\text { the medicine and pre- } \\
\text { scribe placebo (ref. Kent's } \\
\text { 3rd observation). } \\
\text { Amelioration comes } \\
\text { first and the aggrava- } \\
\text { tion comes afterwards: } \\
\text { reassess the case and } \\
\text { prescribe the indicated } \\
\text { medicine in suitable } \\
\text { potency (ref. Kent's 5th } \\
\text { observation). }\end{array}$ & $\begin{array}{l}\text { If the symptoms } \\
\text { are not of a } \\
\text { serious nature, } \\
\text { wait till the new } \\
\text { symptoms pass } \\
\text { off. Then select } \\
\text { another indicated } \\
\text { medicine after } \\
\text { reassessing the } \\
\text { case. } \\
\text { If the symptoms } \\
\text { are of serious } \\
\text { nature, reassess } \\
\text { the case and } \\
\text { prescribe the } \\
\text { indicated remedy } \\
\text { (ref. Kent's } 10 \text { th } \\
\text { observation). } \\
\text { In case new } \\
\text { symptoms keep } \\
\text { on adding and } \\
\text { patient's condi- } \\
\text { tion deteriorates } \\
\text { further, the case } \\
\text { may be referred } \\
\text { for appropriate } \\
\text { medical care. }\end{array}$ & $\begin{array}{l}\text { In case there is no per- } \\
\text { ceptible change (neither } \\
\text { worse nor better) for a } \\
\text { considerable time after } \\
\text { administration of the } \\
\text { medicine, same medi- } \\
\text { cine to be repeated in } \\
\text { the next higher potency. } \\
\text { In case there is no } \\
\text { perceptible improve- } \\
\text { ment after adequate } \\
\text { repetition of medicine } \\
\text { in different potencies, } \\
\text { the investigator must } \\
\text { look for any obstacle(s) } \\
\text { to cure and steps may } \\
\text { be initiated to remove } \\
\text { them. A record of such } \\
\text { advice given to and/or } \\
\text { followed by the patient } \\
\text { is to be kept in the case } \\
\text { follow-up forms. In case } \\
\text { no such obstacle(s) is } \\
\text { found, change of medi- } \\
\text { cine is to be considered. }\end{array}$ & \\
\hline
\end{tabular}

\section{Protocol Amendment}

Protocol amendments will be possible only in exceptional cases (e.g., where the health or well-being of the patient is affected) and only after authorization by the authority. Every amendment must be justified in writing and signed by all those concerned.

\section{Expected Outcomes}

The results of the study will be able to predict the role of homoeopathic treatment as an add-on to conventionally treated cancer patients to minimize the suffering other than cancer and the after effects of chemotherapy and radiation therapy.

\section{Discussion}

A global burden of disease (GBD) study published in The Lancet Oncology ${ }^{54}$ reported that of the northeastern states of India (with a population of 45 million people), particularly the states of Mizoram, Meghalaya, Arunachal Pradesh, and Assam have the highest burden of cancer in terms of age-standardized incidence, mortality, and low survival rates. As per the GBD report the high disability-adjusted life years
(DALYs) shown in the GBD in the northeastern region states mainly are contributed by cancers of stomach, esophagus, hypopharynx, gallbladder, lung, and breast. According to the latest report of PBCR (2012-2014, PBCR, NCRP-ICMR), esophageal cancer was observed as the topmost common cancer in all northeastern states compared with mainland India. Cancer is a life-threatening illness which affects the patients and their surroundings in all aspects-physically, emotionally, and also financially. PBCR of 2012 to 2014 recommends radiotherapy and palliative care for the treatment of cancer. Palliative care is an approach that improves the QoL of patients (adults and children) and their families in which homoeopathy can play a key role, with minimum or no adverse effects. Homeopathy can be successfully integrated in supportive care integrative oncology service ${ }^{18-20}$ for palliative care, for better QoL, and to increase the chances of survival in cancer patients. Homoeopathic remedies can alleviate chemotherapy and radiation therapy side effects such as nausea, vomiting, fatigue, loss of appetite, depression, radiation-induced mucositis, and skin complaints.

The potential of homoeopathic medicines in preclinical and clinical stages of cancer has not been vastly explored. However, some preclinical studies have demonstrated the significant anticancer properties of homoeopathic medicines on different cell lines. ${ }^{1-10}$ 
Study Methodology

(Flowchart No. 1)

Patient having any two of the following suffering viz.;

- Anorexia

- Nausea

- Vomiting

- Diarrhoea

- Constipation

- Cough

- Shortness of breath

- Taste alterations

- Dry mouth

- Mucositis

- Dermatitis

- Conjunctivitis

- Lachrymation

- Hair loss

- Sensory neuropathy

- Flu-like symptoms

- $\quad$ Reduced blood count (but $\mathrm{Hb} \%$ not $<6.5$ $\mathrm{mg} / \mathrm{dL}$ )

- Cramping

- Urinary frequency

- Vaginal irritation

- Impotence

- Skin redness

- Fatigue

- Myalgia

- Anxiety

- Depression, drowsiness
Patients reporting with complaints other than cancer itself and suffering from the after-effects of cancer treatment with chemotherapy and radiation therapy shall be screened for treatment.

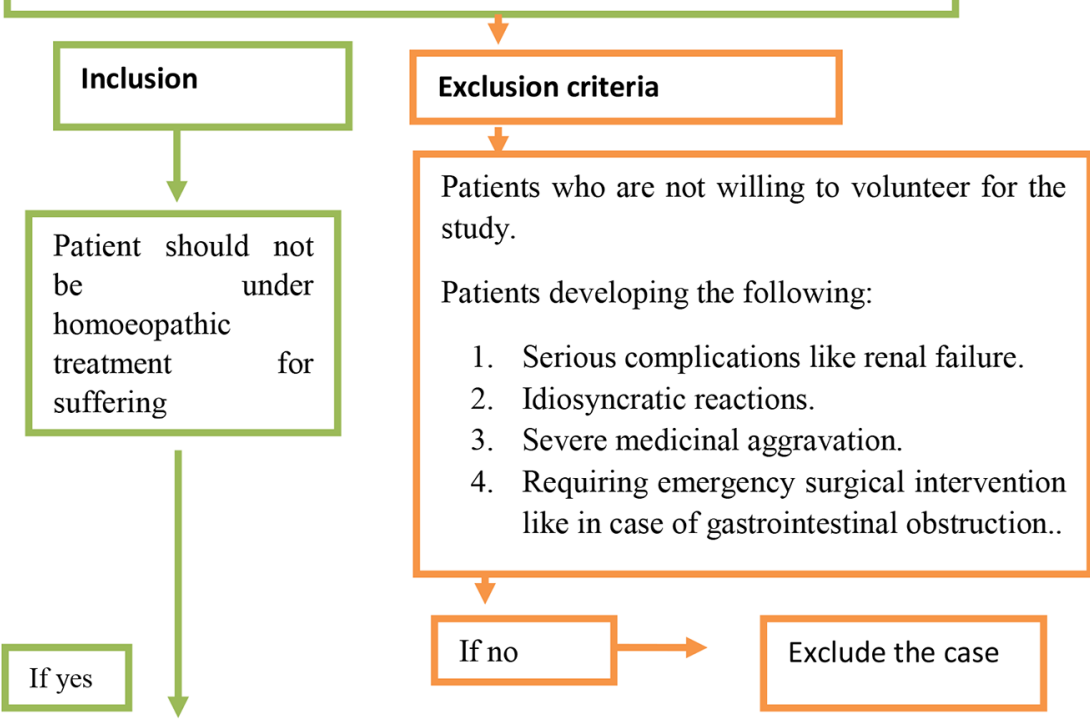

Enrolment of patient

Homoeopathic case-taking and administration of medicine

- Case-taking on the basis of totality of symptoms.

- Repertorization using Hompath software.

Only one medicine whose portrait confirms in the Materia Medica shall be selected as the first prescription with justification for the respective patient in centesimal potency $(6 \mathrm{C}, 30 \mathrm{C}$, and $200 \mathrm{C}$ ).
The first dose of the study drug will be administered under direct observation of the study physician in the hospital.

Repetition-Indicated homoeopathic medicine will be repeated as per the need of each case depending upon the intensity of symptoms.
Each patient will be followed-up (if necessary telephonically) at entry and on every 3rd day or as per requirement.

\section{Assessment \\ Marked-more than $75 \%$ improvement in symptom score from baseline score.}

Moderate-50\% to less than $75 \%$ improvement in symptom score from baseline

Mild-25\% to less than $50 \%$ improvement in symptom score from baseline score

Not significant-less than $25 \%$ improvement in symptom score from baseline score.

Not improved - no change in symptom score from baseline score after sufficient trial of the best indicated drug has been done.
ESAS-R and EORTC QLQ-C30 shall be filled at entry and on every 3rd day till 3 months.

Complete hemogram is to be done at entry and on every month till 3 months.

Worse - increase of symptom score from Base line score.

Status quo - no change of score from baseline score.

Referred-referred for other therapy in the eventuality of any adverse event.

Withdrawal-case withdraws consent or refuses for further treatment.

Drop out-does not fulfill conditions as per the protocol.

Fig. 1 Study methodology. 
A review was conducted to determine the Cochrane reviewers' opinion if any evidence exists for the effects of conventional cancer therapies by homoeopathy. After exploring, the database revealed that 7 out of the total 8 controlled trials in this area of study were placebo controlled and 1 was against an active treatment. In the 8 controlled trials, outcomes of 664 people are covered who were suffering from the adverse effects of conventional cancer therapies like radiotherapy, chemotherapy, or breast cancer treatment. Two out of 8 trials had positive outcomes toward homoeopathy. One of these outcomes proved the superiority of homeopathic mother tincture of calendula for the prevention of dermatitis from radiotherapy, while comparing with the effects of topical corticosteroid..$^{50}$ In a study of 82 patients, randomly assigned Cobaltum 30C or Causticum 30C proved to be beneficial in significant reduction in the dermatological reactions to the radiotherapy when compared with placebo. ${ }^{27}$ Twenty-five women were treated with individualized homeopathic medicines for radiotherapy-induced itching at the University of Vienna's Department of Radiotherapy and Radiobiology. After assessment for 27 days, homoeopathic treatment had been successful in 21 women enrolled in the study. ${ }^{25}$

The preclinical research on homoeopathy has evaluated the beneficial effects of homeopathic medicines against radiation. ${ }^{55}$ Ginseng 6X, 30X, and 200X and Ruta graveolens 30X and 200X were administered before and after exposure of 100 to 200 rad of X-ray (sublethal doses) to albino mice and then evaluated after 24,48 , and 72 hours. Mice given any of these homeopathic medicines experienced significantly less chromosomal or cellular damage as compared with the placebo as treatment. Ginseng 30X and 200X, in particular, had significant and substantial benefits. ${ }^{55,56}$ There are evidence of positive effects of homeopathic crude doses of Ginseng which finds that it repairs DNA after radiation exposure. ${ }^{57}$

In another study, when albino guinea pigs were exposed to small doses of X-ray, it reddened the skin. Homeopathic medicine Apis mellifica 7C or 9C showed protective effect and an almost 50\% restorative effect on X-ray-induced redness of the skin. ${ }^{58}$ Also, postsurgical complication of cancer cases may be managed by homoeopathy. A study suggested that patients who underwent total mastectomy suffered from postoperative seroma and bleeding. Arnica montana reduced the seroma and bleeding in those cases. ${ }^{59}$

\section{Conclusion}

These studies have reported the positive outcome of homoeopathy in cancer; however, the effectiveness in preclinical and clinical stages of cancer needs more exploration. The results of the present study will be able to predict the role of homoeopathic treatment as an add-on to conventionally treated cancer patients to minimize the suffering other than cancer and the after effects of chemotherapy and radiation therapy. If found significant, this could prove to be a contribution in health care system in handling cancer cases which are very difficult to treat. Further, the cost-effectiveness of homoeopathy will enable developing countries in controlling such a disease effectively.

Funding

None declared.

\section{Conflict of Interest}

None declared.

\section{Acknowledgment}

With profound reverence and gratitude, the authors would like to thank Dr. Anil Khurana, Director General, Central Council for Research in Homoeopathy, New Delhi, Govt. of India. The authors also acknowledge the technical expertise from Dr. Alok Mishra, Assistant Professor and Visiting Physician, Mahesh Bhattacharyya Homoeopathic Medical College and Hospital (Govt. Of West Bengal), former Research Officer (H)/Scientist-1, DACRRI (Govt. of India)

\section{References}

1 Torres A, Vargas Y, Uribe D, et al. Pro-apoptotic and anti-angiogenic properties of the $\alpha / \beta$-thujone fraction from Thuja occidentalis on glioblastoma cells. J Neurooncol 2016;128(1):9-19

2 Bishayee K, Mondal J, Sikdar S, Khuda-Bukhsh AR. Condurango (Gonolobus condurango) extract activates fas receptor and depolarizes mitochondrial membrane potential to induce ROS-dependent apoptosis in cancer cells in vitro: CE-treatment on HeLa: a ROS-dependent mechanism. J Pharmacopuncture 2015;18(3):32-41

3 Arora S, Tandon S. DNA fragmentation and cell cycle arrest: a hallmark of apoptosis induced by Ruta graveolens in human colon cancer cells. Homoeopathy 2015;104(1):36-47

4 Sikdar S, Kumar Saha S, Rahman Khuda-Bukhsh A. Relative apoptosis-inducing potential of homeopathic Condurango $6 \mathrm{C}$ and $30 \mathrm{C}$ in $\mathrm{H} 460$ lung cancer cells in vitro-apoptosis-induction by homeopathic Condurango in H460 cells. J Pharmacopuncture 2014;17(1):59-69

5 Banerjee A, Pathak S, Biswas SJ, et al. Chelidonium majus $30 \mathrm{C}$ and $200 \mathrm{C}$ in induced hepatotoxicity in rats. Homeopathy 2010;99(3):167-176

6 Bhattacharjee PB, Khuda-Bukhsh AR. Homeopathic drugs natrum sulphuriucm and carcinosin prevent azo dye-induced hepatocarinogenesis in mice. Ind J Res Hom 2009;3(4):1-15

7 Bhattacharjee N, Pathak S, Khuda-Bukhsh AR. Amelioration of carcinogen-induced toxicity in mice by administration of a potentized homeopathic drug, natrumsul phuricum 200. Evid Based Complement Alternat Med 2009;6(1):65-75

8 Pathak S, Kumar Das J, Biswas SJ, Khuda-Bukhsh AR. Protective potentials of a potentized homoeopathic drug, lycopodium-30, in ameliorating azo dye induced hepatocarcinogenesis in mice. CCRH Quarterly Bulletin 2006;28(4):1-13

9 Biswas SJ, Pathak S, Bhattacharjee N, Das JK, Khuda-Bukhsh AR. Efficacy of the potentized homeopathic drug, Carcinosin 200, fed alone and in combination with another drug, Chelidonium 200, in amelioration of p-dimethylaminoazobenzene-induced hepatocarcinogenesis in mice. J Altern Complement Med 2005;11(5):839-854

10 Biswas SJ, Khuda-Bukhsh AR. Evaluation of protective potentials of a potentized homeopathic drug, Chelidonium majus, during azo dye induced hepatocarcinogenesis in mice. Indian J ExpBiol 2004;42(7):698-714 
11 Saha S, Hossain DM, Mukherjee S, et al. Calcarea carbonica induces apoptosis in cancer cells in p53-dependent manner via an immuno-modulatory circuit. BMC Complement Altern Med 2013;13:230

12 Saha S, Bhattacharjee P, Mukherjee S, et al. Contribution of the ROS-p53 feedback loop in thuja-induced apoptosis of mammary epithelial carcinoma cells. Oncol Rep 2014;31(4):1589-1598

13 Saha S, Bhattacharjee P, Guha D, et al. Sulphur alters NFKB-p300 cross-talk in favour of p53-p300 to induce apoptosis innon-smallcelllungcarcinoma.IntJOncol2015;47(2):573-582

14 Rajendran ES. Homeopathy as a supportive therapy in cancer. Homeopathy 2004;93(2):99-102

15 Karp JC, Sanchez C, Guilbert P, Mina W, Demonceaux A, Curé H. Treatment with Ruta graveolens $5 \mathrm{CH}$ and Rhus toxicodendron $9 \mathrm{CH}$ may reduce joint pain and stiffness linked to aromatase inhibitors in women with early breast cancer: results of a pilot observational study. Homeopathy 2016;105(4):299-308

16 World Health Organization. WHO definition of palliative care Accessed February 28, 2019 at http://www.who.int/newsroom/fact-sheets/detail/palliative-care

17 Bornhoft G, Matthiessen PF, Homeopathy in HealthcareEffectiveness, Appropriateness, Safety, Costs. Berlin, Germany: Springer; 2011

18 Samuels N, Freed Y, Weitzen R, et al. Feasibility of homeopathic treatment for symptom reduction in an integrative oncology service. Integr Cancer Ther 2018;17(2):486-492

19 Bosco F, Cidin S, Maceri F. Ghilli M, Roncella M, De Simone L. An integrated approach with homeopathic medicine and electro-acupuncture in anaesthesiology during breast cancer surgery:casereports.JPharmacopuncture2018;21(2):126-131

20 Gaertner K, Müllner M, Friehs H, et al. Additive homeopathy in cancer patients: Retrospective survival data from a homeopathic outpatient unit at the Medical University of Vienna. Complement Ther Med 2014;22(2):320-332

21 Poole J. Individualised homeopathy after cancer treatment. Nurs Times 2014;110(41):17-19

22 Jacobs J, Herman P, Heron K, Olsen S, Vaughters L. Homeopathy for menopausal symptoms in breast cancer survivors: a preliminary randomized controlled trial. J Altern Complement Med 2005;11(1):21-27

23 Huszno J, Budryk M, Kołosza Z, Nowara E. The risk factors of toxicity during chemotherapy and radiotherapy in breast cancer patients according to the presence of BRCA gene mutation. Contemp Oncol (Pozn) 2015;19(1):72-76

24 ShajiKumarRT,SachdevaJ,LambaCD.Acaseofradiation-induced mucositis. Indian J Res Homoeopathy 2017;11:257-261

25 Schlappack 0. Homeopathic treatment of radiation-induced itching in breast cancer patients. A prospective observational study. Homeopathy 2004;93(4):210-215

26 Balzarini A, Felisi E, Martini A. De Conno F. Efficacy of homeopathic treatment of skin reactions during radiotherapy for breast cancer: a randomised, double-blind clinical trial. $\mathrm{Br}$ Homeopath J 2000;89(1):8-12

27 Kulkarni A, Nagarkar BM, Burde GS. Radiation protection by use of homoeopathic medicines. Proceedings from the 8th Conference of Radiation Oncologists of India, Bombay, December 1986, reported in Hahnemann Homoeopath Sand, 1988 Jan, 12, 1, 20-3

28 Rostock M, Naumann J, Guethlin C, Guenther L, Bartsch HH, Walach $\mathrm{H}$. Classical homeopathy in the treatment of cancer patients-a prospective observational study of two independent cohorts. BMC Cancer 2011;11:19

29 Pathak S, Kumar Das J, Jyoti Biswas S, Khuda-Bukhsh AR. Protective potentials of a potentized homeopathic drug, Lycopodium-30, in ameliorating azo dye induced hepatocarcinogenesis in mice. Mol Cell Biochem 2006;285(1-2):121-131

30 Samanta S, De AU, Tarafder PK, Jha T. Search for potential anticancer agents: evaluation of anticancer activity of
Carcinosin, Apis and Thuja. Indian Journal of Research in Homoeopathy 2008;2(1):38-41

31 Pathak S, Banerjee A, Paul S, Khuda-Bukhsh AR. Protective potentials of a plant extract (Lycopodium clavatum) on mice chronically fed hepato-carcinogens. Indian J Exp Biol 2009;47(7):602-607

32 Pathak S, Bhattacharjee N, Das JK, et al. Supportive evidence for the anticancerous potential of alternative medicine against hepatocarcinogenesis in mice. Forsch Komplement Med 2007;14(3):148-156

33 Ghosh S, Bishayee K, Paul A, et al. Homeopathic mother tincture of Phytolacca decandra induces apoptosis in skin melanoma cells by activating caspase-mediated signaling via reactive oxygen species elevation. J Integr Med 2013;11(2):116-124

34 Samadder A, Das S, Das J, Paul A, Boujedaini N, Khuda-Bukhsh AR. The potentized homeopathic drug, Lycopodium clavatum (5C and 15C) has anti-cancer effect on hela cells in vitro.J Acupunct Meridian Stud 2013;6(4):180-187

35 Chakraborty D, Ghosh S, Bishayee K, Mukherjee A, Sikdar S, Khuda-Bukhsh AR. Antihyperglycemic drug Gymnema sylvestre also shows anticancer potentials in human. Integr Cancer Ther 2013;12(5):433-441

36 Arora S, Aggarwal A, Singla P, Jyoti S, Tandon S. Anti-proliferative effects of homeopathic medicines on human kidney, colon and breast cancer cells. Homeopathy 2013;102(4):274-282

37 Mukherjee A, Boujedaini N, Khuda-Bukhsh AR. Homeopathic Thuja 30C ameliorates benzo(a)pyrene-induced DNA damage, stress and viability of perfused lung cells of mice in vitro. J Integr Med 2013;11(6):397-404

38 Arora S, Tandon S. DNA fragmentation and cell cycle arrest: a hallmark of apoptosis induced by Ruta graveolens in human colon cancer cells. Homeopathy 2015;104(1):36-47

39 Mondal J, Samadder A, Khuda-Bukhsh AR. Psorinum 6× triggers apoptosis signals in human lung cancer cells. J Integr Med 2016;14(2):143-153

40 Wani K, Shah N, Prabhune A, Jadhav A, Ranjekar P, Kaul-Ghanekar R. Evaluating the anticancer activity and nanoparticulate nature of homeopathic preparations of Terminalia chebula. Homeopathy 2016;105(4):318-326

41 Chatterjee A, Biswas J. A homeopathic approach to treat patients with advanced gallbladder, periampullary, and liver carcinomas: a report of 3 cases. J Altern Complement Med 2012;18(2):180-186

42 Kulkarni A, Nagarkar BM, Burde GS. Radiation protection by use of homoeopathic medicines. Hahnemann Homoeopath Sandesh 1988;12(1):20-23

43 Pathak S, Multani AS, Banerji P, Banerji P. Ruta 6 selectively induces cell death in brain cancer cells but proliferation in normal peripheral blood lymphocytes: A novel treatment for human brain cancer. Int J Oncol 2003;23(4):975-982

44 Central Council for Research in Homeopathy. Clinical evaluation of homoeopathic medicines along with Iscador therapy in managing malignant diseases. In: Clinical Research StudiesSeries III. New Delhi, India: Central Council for Research in Homeopathy; 2010 24-35

45 Chatterjee A, Biswas J, Chatterjee A, Sudin B, Mukhopadhyay $B$, Mandal S. Psorinum therapy in treating stomach, gall bladder, pancreatic, and liver cancers: a prospective clinical study. Evid Based Complement Alternat Med 2011. Doi: $10.1155 / 2011 / 724743$

46 Frenkel M, Mishra BM, Sen S, et al. Cytotoxic effects of ultra-diluted remedies on breast cancer cells. Int J Oncol 2010;36(2):395-403

47 Frass $\mathrm{M}$, Friehs $\mathrm{H}$, Thallinger $\mathrm{C}$, et al. Influence of adjunctive classical homeopathy on global health status and subjective wellbeing in cancer patients-a pragmatic randomized controlled trial. Complement Ther Med 2015;23(3):309-317 
48 Brulé D, Gillmeister B, Lee M, et al. A feasibility pilot trial of individualized homoeopathic treatment of fatigue in children receiving chemotherapy. Integr Cancer Ther 2016;15(4):495-501

49 Bao Y, Kong X, Yang L, et al. Complementary and alternative medicine for cancer pain: an overview of systematic reviews. Evid Based Complement Alternat Med 2014;2014:170396

50 Kassab S, Cummings M, Berkovitz S, van Haselen R, Fisher P. Homeopathic medicines for adverse effects of cancer treatments. Cochrane Database Syst Rev 2009;2(2):CD004845

51 Pérol D, Provençal J, Hardy-Bessard AC, et al. Can treatment with Cocculine improve the control of chemotherapy-induced emesis in early breast cancer patients? A randomized, multi-centered, double-blind, placebo-controlled phase III trial. BMC Cancer 2012;12:603

52 Milazzo S, Russell N, Ernst E. Efficacy of homeopathic therapy in cancer treatment. Eur J Cancer 2006;42(3):282-289

53 Thompson EA, Reillly D. The homeopathic approach to symptom control in the cancer patient: a prospective observational study. Palliat Med 2002;16(3):227-233

54 India State-Level Disease Burden Initiative Cancer Collaborators. The burden of cancers and their variations across the states of
India: the Global Burden of Disease Study 1990-2016. Lancet Oncol 2018;19:1289-1306

55 Khuda-Bukhsh AR, Banik S. Assessment of cytogenetic damage in X-irradiated mice and its alteration by oral administration of potentized homeopathic drug, Ginseng D200. Berlin Journal of Research in Homeopathy 1991;1(4/5):254

56 Khuda-Bukhsh AR, Maity S. Alteration of cytogenetic effects by oral administration of potentized homeopathic drug, Ruta graveolens in mice exposed to sub-lethal X-radiation. Berlin Journal of Research in Homeopathy 1991;1(4/5):264

57 Kim TH, Lee YS, Cho CK, Park S, Choi SY, Yool SY. Protective effect of ginseng on radiation-induced DNA double strand breaks and repair in murine lymphocytes. Cancer Biother Radiopharm 1996;11(4):267-272

58 Bildet J, Guyot M, Bonini F, et al. Demonstrating the effects of Apis mellifica and Apium virus dilutions on erythema induced by U.V. radiation on guinea pigs. Berlin Journal of Research in Homeopathy 1990;1:28

59 Sorrentino L, Piraneo S, Riggio E, et al. Is there a role for homeopathy in breast cancer surgery? A first randomized clinical trial on treatment with Arnica montana to reduce post-operative seroma and bleeding in patients undergoing total mastectomy. J Intercult Ethnopharmacol 2017;6(1):1-8 